\title{
Assessing Sensitivity of Hyperspectral Sensor to Detect Oils with Sea Ice
}

\author{
Bingxin Liu, Ying Li, Qiang Zhang, and Liang Han \\ Environmental Information Institute, Navigation College, Dalian Maritime University, Dalian 116026, China \\ Correspondence should be addressed to Ying Li; yldmu@dlmu.edu.cn
}

Received 30 January 2016; Revised 9 March 2016; Accepted 15 March 2016

Academic Editor: Khalique Ahmed

Copyright (C) 2016 Bingxin Liu et al. This is an open access article distributed under the Creative Commons Attribution License, which permits unrestricted use, distribution, and reproduction in any medium, provided the original work is properly cited.

The reflectance of two commonly used oils, crude oil and diesel, is measured under various conditions: on a water surface, among pack ice, and on/beneath compact ice. The spectral characteristics of each oil are analyzed using the results from these measures. In conjunction with estimated noise thresholds of the sensor environment, the theoretical potential to identify oil is assessed for the hyperspectral Hyperion. The hyperspectral sensor is more sensitive to the crude oil than to diesel under all conditions. The visible and infrared bands, from $468 \mathrm{~nm}$ to $933 \mathrm{~nm}$, are more suitable to identify the crude oil. In addition, when the background is pack ice, the infrared region from $1134 \mathrm{~nm}$ to $1326 \mathrm{~nm}$ is another potential useful zone. Through the visible-to-infrared bands, the sensitivity to the existence of diesel is inferior to that of crude oil. Relatively, the bands greater than $1134 \mathrm{~nm}$ have the potential to separate diesel from the water or sea ice. These characteristics and sensitivity of oil film in terms of ice and oil type can be effectively used to select suitable bands to distinguish oils from sea water and sea ice.

\section{Introduction}

Climate warming has influenced the increasing decline of the ice-covered area in the Arctic region year by year. From 2002 to 2011, the ice area shrunk 82,800 km² each year [1]. In 2007 , the northeast and northwest channels in this area were opened for the first time. In this context, the navigation of the Arctic waterway became possible. A total of 71 ships carrying 1,355,897 tons of cargo sailed via this shortcut between Europe and Asia in 2013 [2]. With the development of the Arctic and the exploitation of resources in the Antarctic, the numbers of oil drilling platforms and oil tankers have increased rapidly [3], increasing the possibility of oil spill in iceinfested waters [4]. For China, Bohai Sea and its surrounding waters distribute into many oilfields, such as Liaohe oilfield, Dagang oilfield, Shengli oilfield, Jinzhou 9-3, and other large oilfields or offshore oil and gas fields. At the same time, owing to the strong and stable Mongolian cold high-pressure control, Bohai Sea freezes every winter. Oil spills in iceinfested waters in this area have become a subject of great concern to corporations, local residents, and government agencies $[5,6]$.
Numerous studies have been conducted in the past years on the monitoring of oil spills in open waters by using remote sensing $[7,8]$. The methods used include synthetic aperture radar (SAR) [9-11], multiple and hyperspectral visible-near infrared (VNIR) [7, 12-18], laser-induced fluorescence [8, 19], and thermal infrared [20-22]. However, studies on the monitoring of oil spill in waters with sea ice are much fewer.

For oil spill monitoring in the area of sea ice-infested waters, the VNIR remote sensing method has much more potential than SAR. Given the presence of sea ice, the conventional effective remote sensing methods, such as SAR, cannot identify oil slicks in waters with sea ice [5, 23-26]. Based on the reflectance and emissivity of the objects, however, VNIR remote sensing can eliminate oil slicks from the waters and sea ice [27]. Fingas and Brown monitored the offshore oil slicks off the Canadian coast [28]. Dick and Fingas used airborne infrared instruments to survey the oils on the waters of Svalbard areas [29]. The airborne spectrometer images were used to extract the characteristics of the sea ice, water, and oil slicks [30].

As a cutting-edge method, hyperspectral remote sensing can distinguish oil slicks from sea ice and water. 


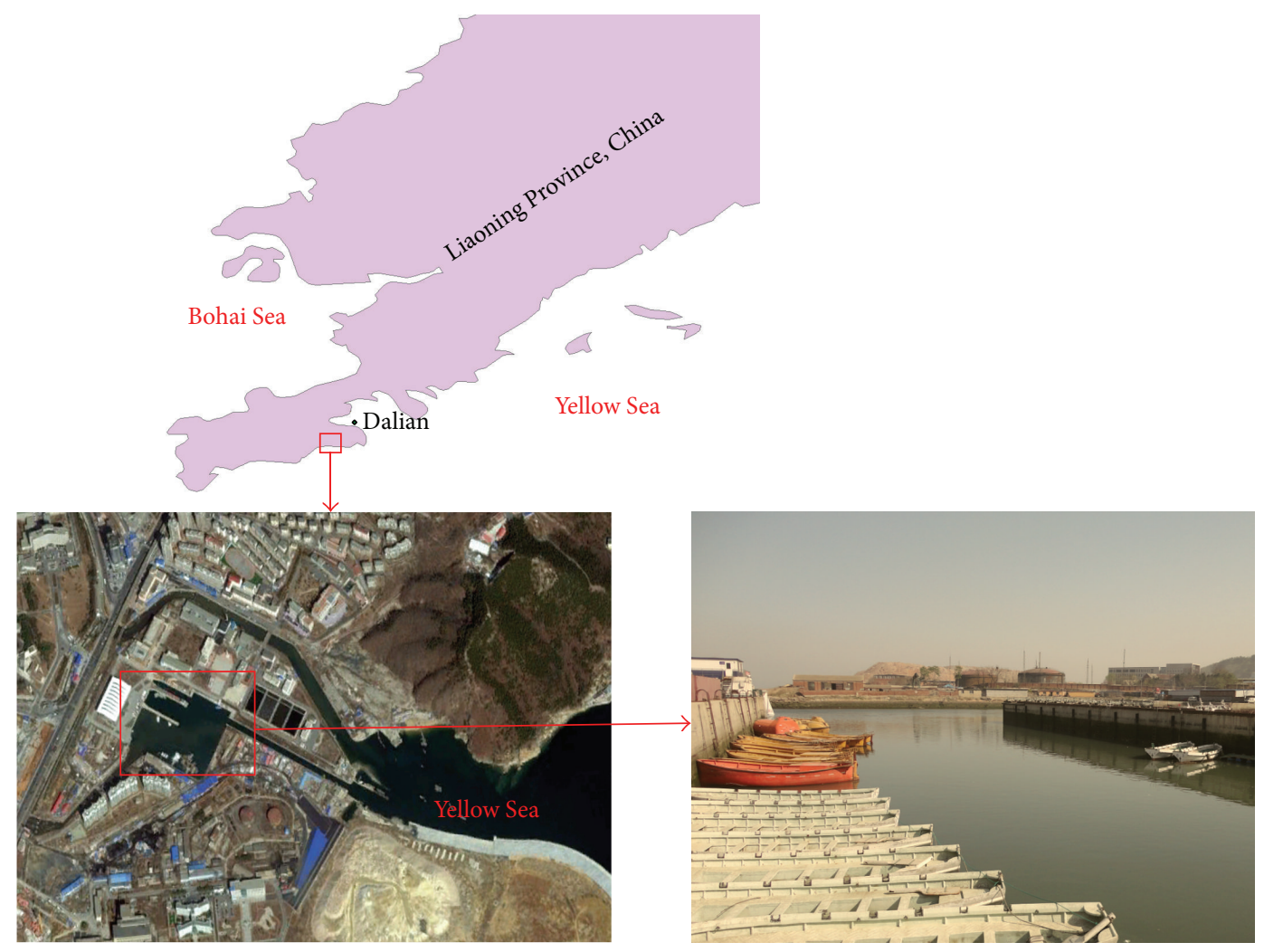

FIGURE 1: Location of study area.

The hyperspectral sensors obtain images containing the continuous reflectance spectra of the objects. By using the features of the spectra, experts may identify a specific issue more accurately. However, limited studies have been performed on the spectral characteristics of oil slicks in iceinfested waters.

To develop a credible and effective response to oil spills in ice-infested waters, in this study, a field experiment was performed on the spectrum of oil film in Dalian ice-infected waters and the sensitivity of hyperspectral sensor bands was analyzed. The results of this study could provide basis for band selection to detect oil spills in ice-infested waters. The sensitivity wavebands could also guide the design of remote sensors for monitoring oil spill.

\section{Methods}

The oil types used in the experiment included crude oil from Liaohe oilfield and diesel used by the vessel of YUKUN. An ASD FieldSpec Pro spectroradiometer was used to obtain the spectral reflectance of the oil film samples. Measurements were recorded in reflectance units computed from illumination intensity measurements of the target and a "Spectralon" Panel. The spectroradiometer has a sampling interval of 1.4$2 \mathrm{~nm}$ and a spectral resolution between 3 and $10 \mathrm{~nm}$. For the purpose of investigating the effect of object type on reflectance through measurements, a fixed viewing geometry with a $90^{\circ}$ incidence angle was maintained.
The experiment site was located in the port waters near Dalian Maritime University (Figure 1). Water depth was $4 \mathrm{~m}$, and thickness of sea ice was $2-3 \mathrm{~cm}$. The experiment was operated between 11:00 am and 12:30 pm at low wind speed.

The images employed in this study were from the Hyperion hyperspectral sensor boarded on satellite EO-1, with the spectrum ranging from $356 \mathrm{~nm}$ to $2577 \mathrm{~nm}, 242$ bands contained, and the spectral resolution approximating $10 \mathrm{~nm}$. Atmospheric correction of the raw data was conducted with the FLAASH module in ENVI4.5 to acquire the reflectance of ground features from Hyperion data.

The response function was used to filter the samples' measured reflectance. The wavelength range and spectral resolution were sampled to the Hyperion sensor. We selected the environmental equivalent noise of homogenous area on the image to represent the instrument noise. The filtered reflectance was then normalized to the noise. The normalized spectra were finally used to analyze the sensor's sensitivity to discriminate oil slacks within sea ice environment (Figure 2).

2.1. Measurement Principles of Spectral Reflectance. Given that most ground features are considered to be non-Lambert reflectors, Nicodemus et al. [31] proposed the bidirectional reflectance distribution function (BRDF) to describe the spectral characteristics of such ground features:

$$
f\left(\theta_{s}, \varphi_{s}, \theta_{v}, \varphi_{v}, \lambda\right)=\frac{d L_{T}\left(\theta_{v}, \varphi_{v}, \lambda\right)}{L_{s}\left(\theta_{s}, \varphi_{s}, \lambda\right) \mu_{s} d \mu_{s} d \varphi_{s}},
$$




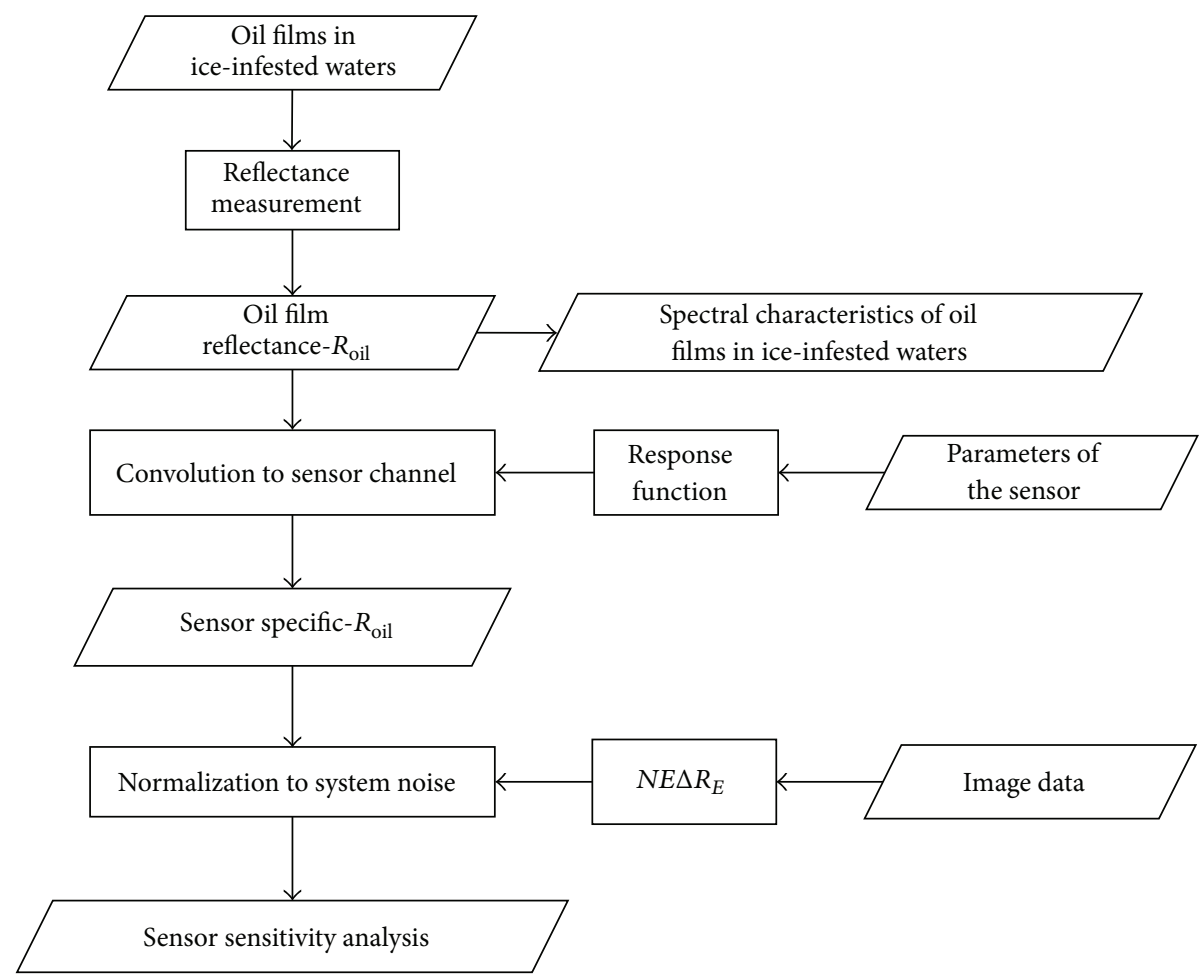

FIGURE 2: Flowchart of process used to conduct spectral sensitivity analysis.

where $\theta_{s}$ is the solar zenith angle, $\theta_{v}$ is the sensor zenith angle, $\varphi_{s}$ is the solar azimuth angle, $\varphi_{v}$ represents the sensor azimuth angle, $\lambda$ is the wavelength, $L_{s}\left(\theta_{s}, \varphi_{s}, \lambda\right)$ is the incident spectral radiance, $d L_{T}\left(\theta_{v}, \varphi_{v}, \lambda\right)$ is the reflected spectral radiance, and $\mu_{s}$ is the cosine of the solar zenith angle.

Although the BRDF provides a superb illustration of the spectral characteristics of non-Lambert reflectors, it can hardly achieve the precise measurement of the incident radiant flux density. On this account, the bidirectional reflectance factor is introduced [32]:

$$
R\left(\theta_{s}, \varphi_{s}, \theta_{v}, \varphi_{v}, \lambda\right)=\frac{d L_{T}\left(\theta_{v}, \varphi_{v}, \lambda\right)}{d L_{L}\left(\theta_{v}, \varphi_{v}, \lambda\right)},
$$

where $d L_{L}\left(\theta_{v}, \varphi_{v}, \lambda\right)$ is the reflected spectral radiance of the Lambert reflector, which is isotropic.

Reference boards are used to simulate Lambert reflectors in the actual measurements, and the reflected spectral radiance of Lambert reflectors is represented by that of the boards. Through this means, the hemispherical directional reflectance of the object is calculated as

$$
R_{O}(\lambda)=\frac{d L_{O}\left(\theta_{v}, \varphi_{v}, \lambda\right)}{d L_{R}(\lambda)} R_{R}(\lambda) .
$$

$R_{O}(\lambda)$ is the reflectance of an object in the observed direction, and $L_{R}(\lambda)$ and $R_{R}(\lambda)$ are the radiance of the reference board and the hemispherical directional reflectance, respectively.
2.2. Spectral Reflectance Measurement. In the experiment, three large ice areas were selected: Area 1, clean sea water without ice, Area 2, compact ice, and Area 3, pack ice. Each area measured $2 \mathrm{~m} \times 2 \mathrm{~m}$ and was divided into two parts: one part was used to measure the reflectance of diesel, and the other part was used to measure that of crude (Table 1).

Before measuring the oil film spectrum, the reflectance of clean sea water, pack ice, and compact ice should be obtained first. After clean water and ice were measured, the reflectance of oil slick with the water and ice was acquired. The measured data included the reflectance of diesel and crude oil film on the water surface, the diesel on and beneath the compact ice, crude oil on the compact ice, diesel among the pack ice, and crude oil among the pack ice with the fractions of $50 \%$ and $90 \%$.

With the use of an ASD spectroradiometer, data were collected quasi-synchronously. Dark current correction of the apparatus was performed before data collection. In the process of measurement, optimizations were implemented at 3-5 min intervals, and the probe was kept vertically downwards and $100 \mathrm{~cm}$ from the surface to measure all the reflectance. Data measurements were repeated 10 times each time to acquire the arithmetic mean values.

In this study, reflectance is the apparent reflectance, which is the ratio of reflected energy to the input energy. In the natural world, the incident and reflected energies received by the sensor are comprised of both reflected energy from the water surface and the sky radiance. Thus, sky radiance was not removed in this study. 
TABLE 1: Scene of the reflectance measurement.

\begin{tabular}{lccc}
\hline & Area 1 & Area 2 & Area 3 \\
\hline- & Clean sea water & Clean compact ice & Clean pack ice \\
a & Diesel on water & Diesel on compact ice & Diesel among pack ice \\
b & Crude oil on water & Crude oil on compact ice & Crude oil among pack ice-50\% \\
& & & Crude oil among pack ice-90\% \\
\hline
\end{tabular}

2.3. Environmental Noise Extraction. The accurate estimation of noise in the sensor-atmosphere-object system enhances the accuracy in acquiring environmental information. To assess the precision of the remote sensing system in extracting environmental variables, the environmental noise equivalent radiance $\left(N E \Delta L_{E}\right)$ and environmental noise equivalent reflectance $\left(N E \Delta R_{E}\right)$ of the remote sensing image need to be calculated. The environmental noise equivalent comprises the signal-to-noise ratio (SNR) and the characteristics of the observed image. $N E \Delta R_{E}$ is used to describe it in our study. $N E \Delta R_{E}$ is correlated with the SNR of the device and concurrently influenced by atmospheric variables, vapor/water interface, sunlight, and the scattering of skylight [33]. Consider

$$
N E \Delta R_{E}=\sigma(R) .
$$

$\sigma(R)$ is the standard deviation of reflectance of various bands in a window covering the relatively homogeneous water area with a large optical depth. The convergence of $\sigma(R)$ can be achieved through the adjustment of window size ( 3 $\times 3,5 \times 5,7 \times 7$ ) [34]. Automated local convergence locator (ALCL), proposed by Wettle et al. [35], was employed to select the location of the window.

The image data used in our study were from the Hyperion sensor boarded on the EO-1 satellite. The data covered a large water area in the Liaodong Bay. Image features in the large area of water showed good uniformity. ALCL was applicable, and $N E \Delta R_{E}$ was extracted to characterize the environmental noise of images [36].

Preprocessing of the hyperspectral remote sensing data, including clipping, band screening, radiation conversion, and atmospheric correction, was carried out to acquire the reflectance. The processing of the Hyperion image by ALCL was achieved with programs written using Interactive Data Language version 7.1 (IDL 7.1). With reference to the parameter selection method in literature [35], two window sizes, $N_{\text {start }}=19$ and $N_{\text {end }}=41$, were selected. The standard deviation of reflectance of areas featured by uniform grayscale distribution in the image was calculated as the value of environmental noise of this image.

2.4. Sensitivity Analysis. The measured reflectance was calculated and denoted as $R_{\mathrm{oil}}$. With the spectral response function of Hyperion data, filtering was performed on $R_{\text {oil }}$, and the responses of Hyperion data to oil films could be acquired and were denoted as $R_{\text {sensor }}$. Consider

$$
R_{\text {sensor }}=\int_{\lambda \min }^{\lambda \max } R_{\text {oil }}(\lambda) f(\lambda) d \lambda,
$$

where $R_{\text {sensor }}$ is the reflectance after filtering using the spectral response function of the sensor and $R_{\text {oil }}$ is the measured reflectance of the oil film. $f(\lambda)$ is the spectral response function of the sensor.

After being normalized by $N E \Delta R_{E}$, the spectra were extended to the discriminable magnitude and marked as $S$. The processed spectra revealed the theoretical sensitivity of Hyperion data in the discrimination of oil slicks and the background.

According to Wettle et al. [33], with $N E \Delta R_{E}$ being the unit of measure, if the absolute value of the difference of two ground features is over 1 at a certain wavelength, and a distinct difference between the two can be observed in the image data acquired by the sensor, then this wavelength is applicable for the discrimination of these two ground features.

\section{Results and Discussions}

3.1. Spectral Reflectance Characteristics. The reflectance of clean sea water, pack ice, and compact ice was measured separately. The spectral shape of their reflectance was similar to that of their characteristics: a large reflection peak at around $580 \mathrm{~nm}$ and 3 absorption valleys at $670 \mathrm{~nm}, 780 \mathrm{~nm}$, and $1000 \mathrm{~nm}$, respectively (Figure 3(a)). The similarity may be mainly caused by the thickness of the ice. However, the ice reflected more energy than the water at the VNIR range, whereas the reflectance of the three declined as the wave lengthened. At the range of 350-470 nm, the reflectance of the compact ice was greater than the reflectance of the water and the reflectance of pack ice. The pack ice also had the highest reflectance from $470 \mathrm{~nm}$ to $1350 \mathrm{~nm}$.

With light diesel oil film, the reflectance spectrum of contaminated sea water showed an extremely small difference from that of clean water. The reflectance was a little higher when the diesel oil film existed at the range of $510 \mathrm{~nm}$ to a longer wavelength (Figure 3(b)). The reflectivity of watercovered crude oil in the whole VNIR band was higher than the reflectivity of the clean water and the reflectivity of light diesel oil-contaminated water. The water with the thick oil film reflected less than that with the thin oil film. Moreover, a valley and a small reflectance peak appeared at 460 and $690 \mathrm{~nm}$, respectively. A significant reflectance wedge peak occurred from $750 \mathrm{~nm}$ to $770 \mathrm{~nm}$ for the crude oil film.

The reflectance spectra of the compact ice with oil film are described in Figure 3(c). When the light diesel oil was on the surface of the ice, the oil's reflectance was lower than the ice before $490 \mathrm{~nm}$ and higher after $510 \mathrm{~nm}$. Lower reflectance appeared before $605 \mathrm{~nm}$ for the oil beneath the sea ice but went higher than the ice from $610 \mathrm{~nm}$ to $1350 \mathrm{~nm}$. 


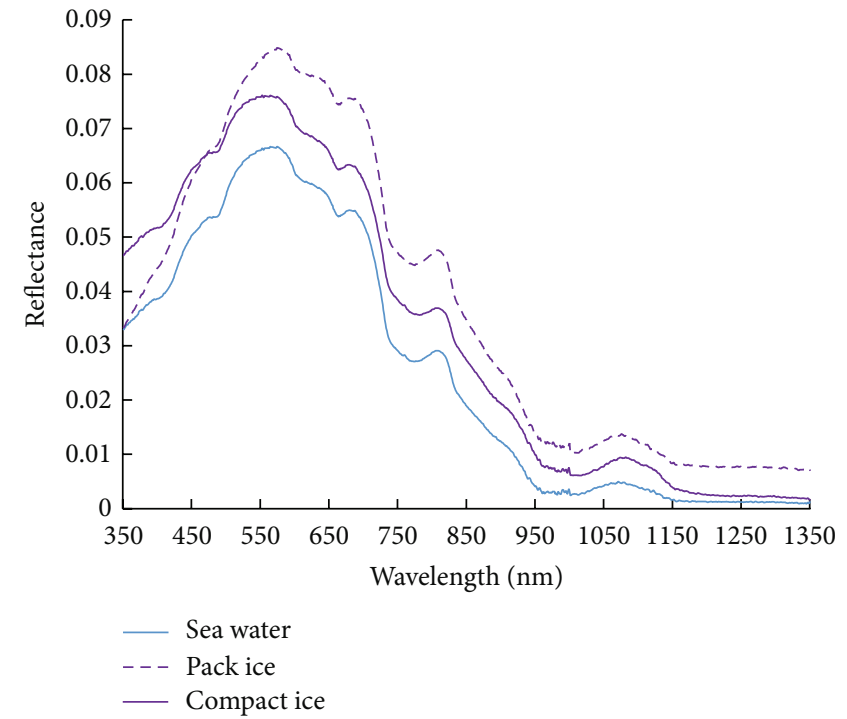

(a)

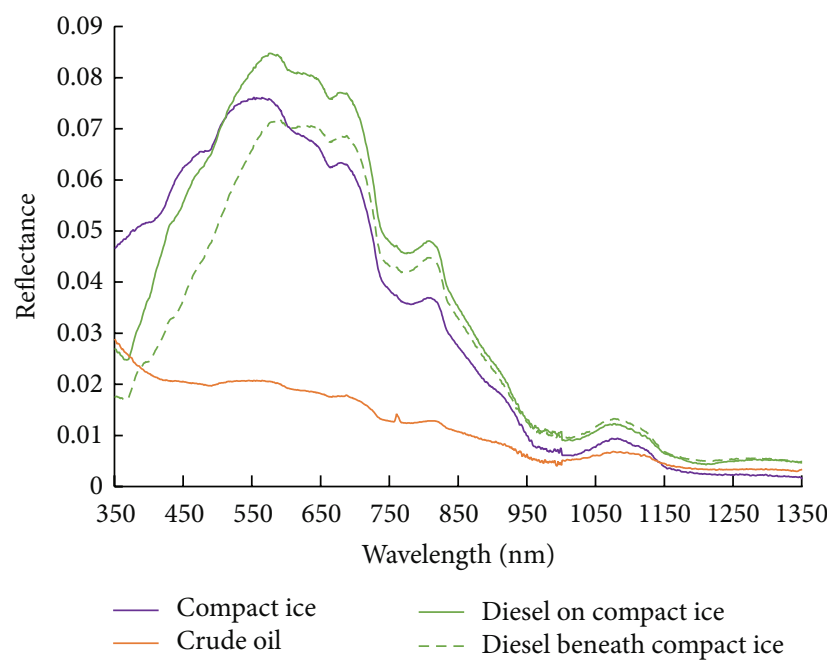

(c)

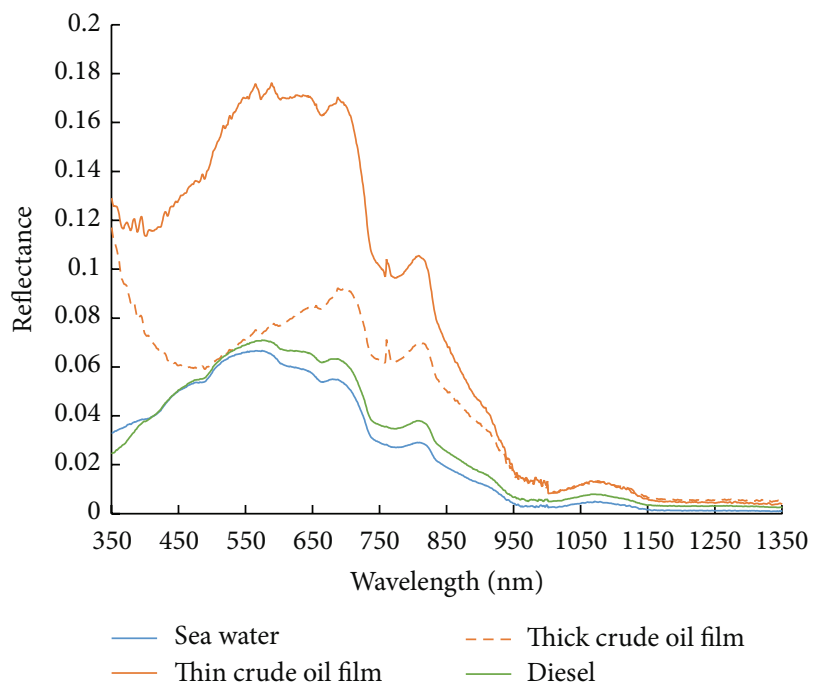

(b)

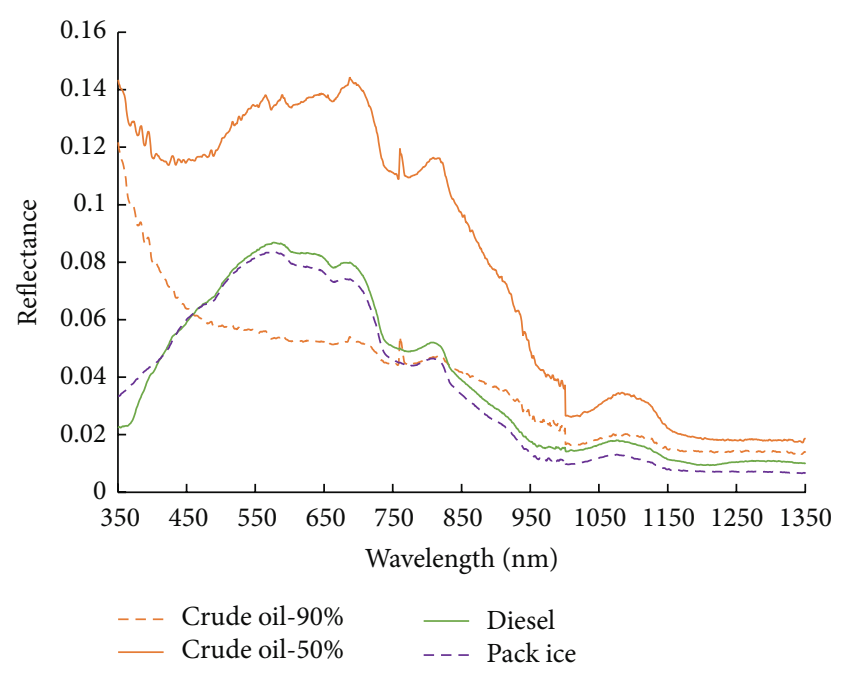

(d)

Figure 3: Spectra of measured reflectance.

For the surface crude oil, the reflectance declined with the growth of the wavelength and was lower than the ice from $350 \mathrm{~nm}$ to $1135 \mathrm{~nm}$. The wedge reflectance peak occurred at the range of $750-770 \mathrm{~nm}$, which appears to be a significant characteristic of crude oil [37].

The reflectance spectra of the pack ice contaminated by the oil film are shown in Figure 3(d). When the crude oil covered $50 \%$ of the view field, it was absorbed at 420 $490 \mathrm{~nm}$ and reflected significantly from $560 \mathrm{~nm}$ to $710 \mathrm{~nm}$. The curve went lower with the increase of wavelength at $820 \mathrm{~nm}$. With the coverage of the crude oil increasing to $90 \%$, the reflectance of the polluted pack ice declined with the growth of wavelength. It was higher than the clean pack ice at the ranges of $350-460 \mathrm{~nm}$ and $760-1350 \mathrm{~nm}$. An absorption valley and a reflectance peak appeared at 1000 and $1100 \mathrm{~nm}$, respectively.

The simulated reflectance from Figure 3 filtered through the sensor response function is shown in Figure 4. For illustrative purposes, the estimated sensor $N E \Delta R_{E}$ is shown in Figure 4. Compared with the measured reflectance in the field, the spectra are smoother. Some minutiae of the measured spectra are eliminated because of the lower spectral resolution of the sensor. However, the shape of all the spectra is generally in accordance with the measured ones. The extracted $N E \triangle R_{E}$ is also depicted compared with the filtered reflectance. The value of $N E \Delta R_{E}$, by comparison, is several orders of magnitude lower than the reflectance of water, ice, and oil. This outcome indicated that the meaningful 


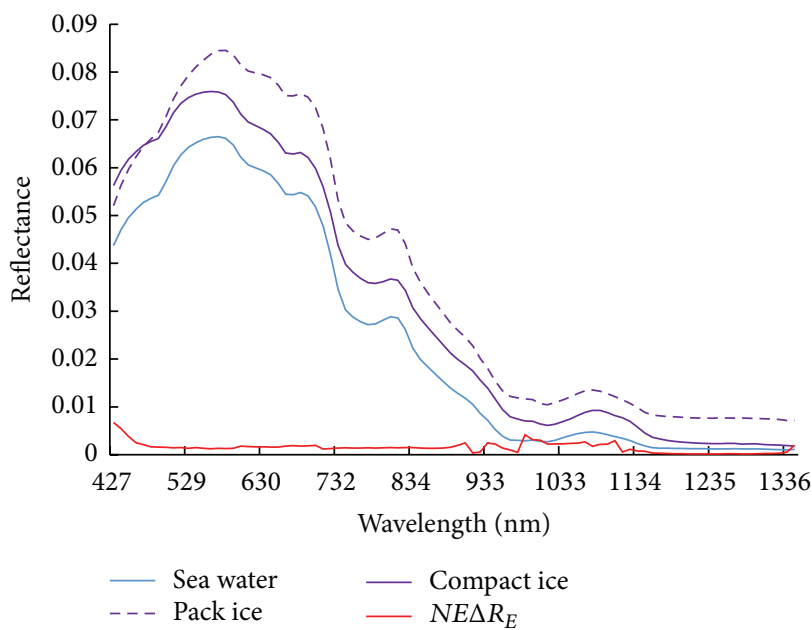

(a)

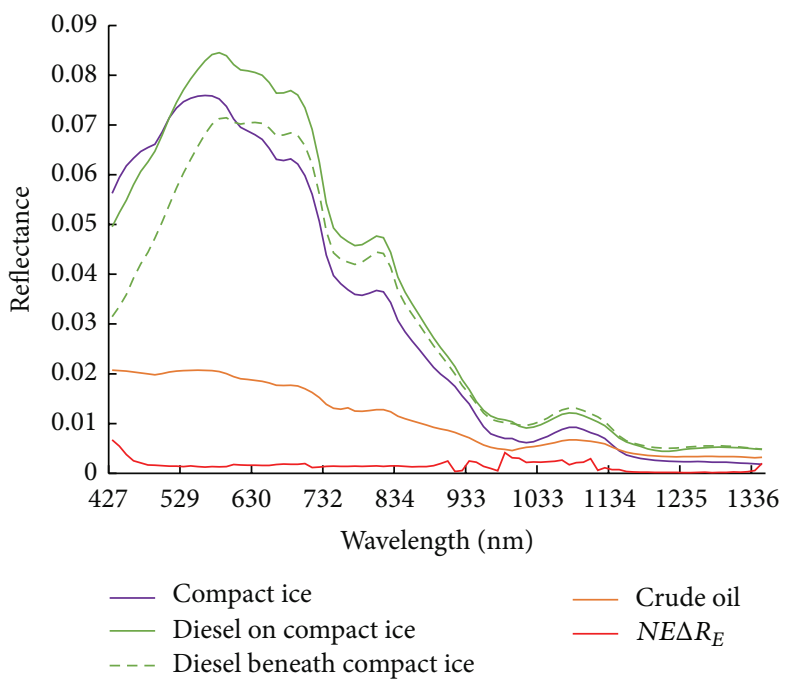

(c)

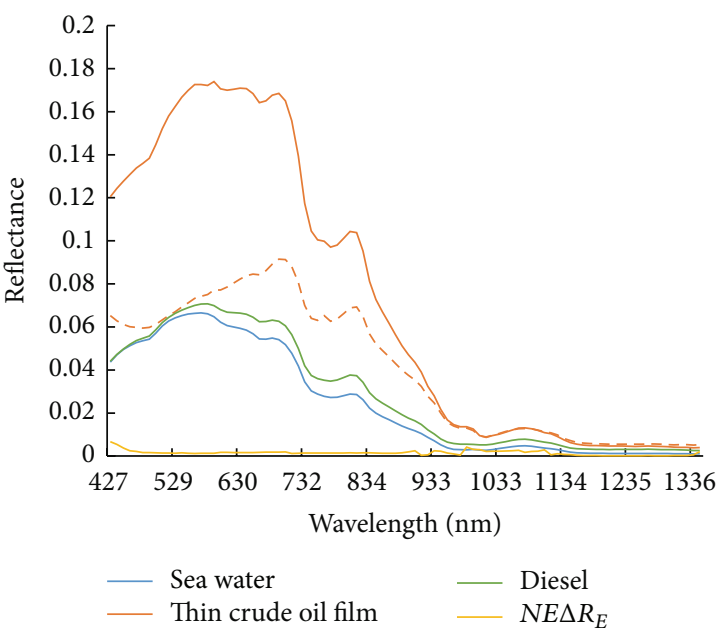

(b)

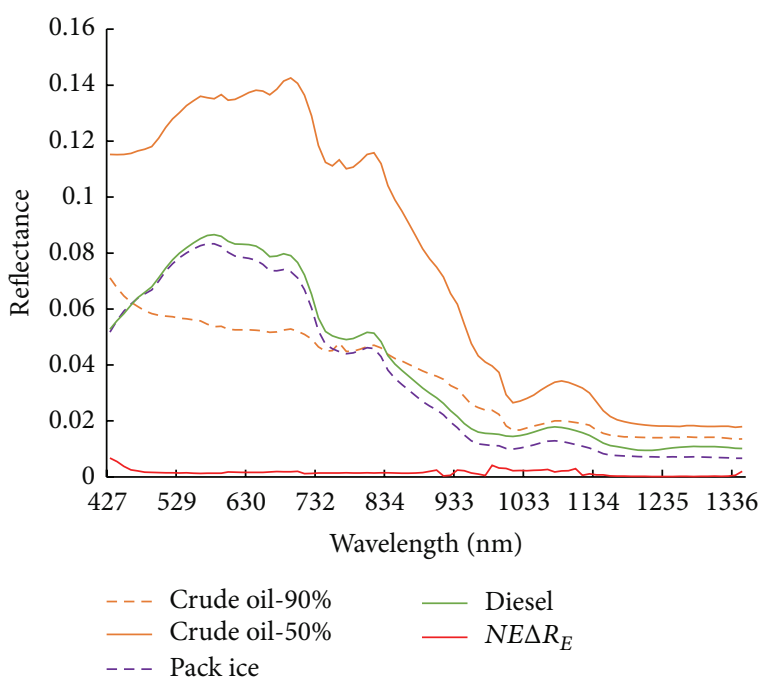

(d)

FIgURE 4: Simulated reflectance spectra on the sensor.

signal could be much more intense than the noise from the environment and the instrument itself.

3.2. Analysis on Hyperspectral Sensitivity to Distinguish Oil Films. Figure 5 shows the simulated reflectance normalized to the $N E \Delta R_{E}$ spectrum established for the hyperspectral remote sensing imagery. The graphs in Figure 5 reveal the theoretical potential of the hyperspectral sensor to detect the measured variability based on the environmental noise parameters. For any given wavelength range, if the difference of $N E \Delta R_{E}$ between two features is greater than 1 , then the features could be theoretically discriminated from each other [33]. As an example, for the range of 498-1346 nm, the compact ice and pack ice are theoretically discernible from the ice-free water (Figure 5(a)). By contrast, the pack ice measurement is within one $N E \Delta R_{E}$ level of the compact ice in the range of $427-498 \mathrm{~nm}$ and, therefore, not detectable. Following this reasoning, the wavelength would have to be greater than $498 \mathrm{~nm}$ to be used as a potential band to discriminate ice from water.

The $N E \Delta R_{E}$ graph for the oil on the water surface (Figure 5(b)) reveals that the slight difference among water, diesel oil film, and thick crude oil film is not detectable by the bands in the range of $427-600 \mathrm{~nm}$, and the $N E \Delta R_{E}$ normalized spectra are all within one $N E \Delta R_{E}$. At the other bands, the diesel and thick crude oil film could be detected theoretically. The reason for the phenomenon may be that the water absorbs almost all the longer wavelength light, while the oil films reflect [38]. The thin crude oil film reflects most of the light through the short wavelength visible light to the nearinfrared light, while the water absorbs the light. Thus, most of the bands could be used to discriminate thin crude oil film from the water. 


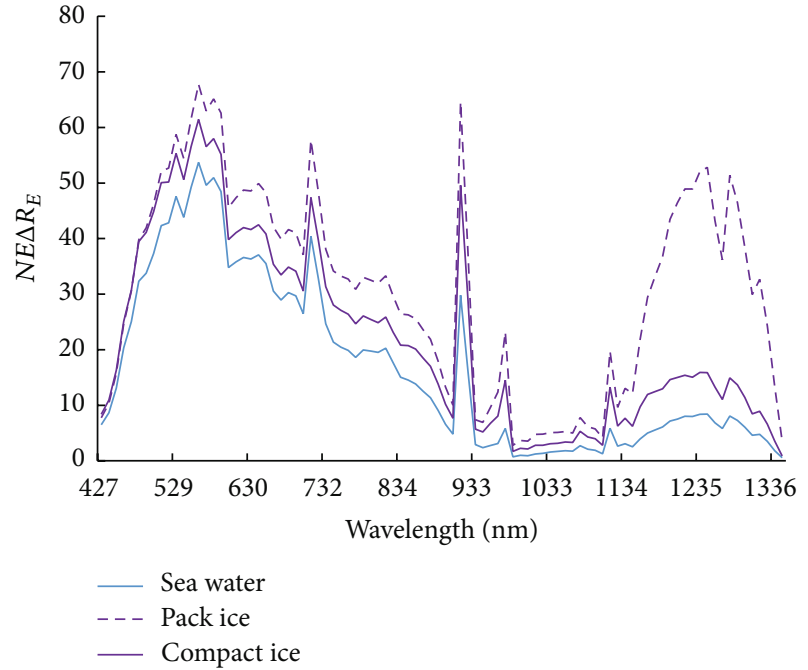

(a)

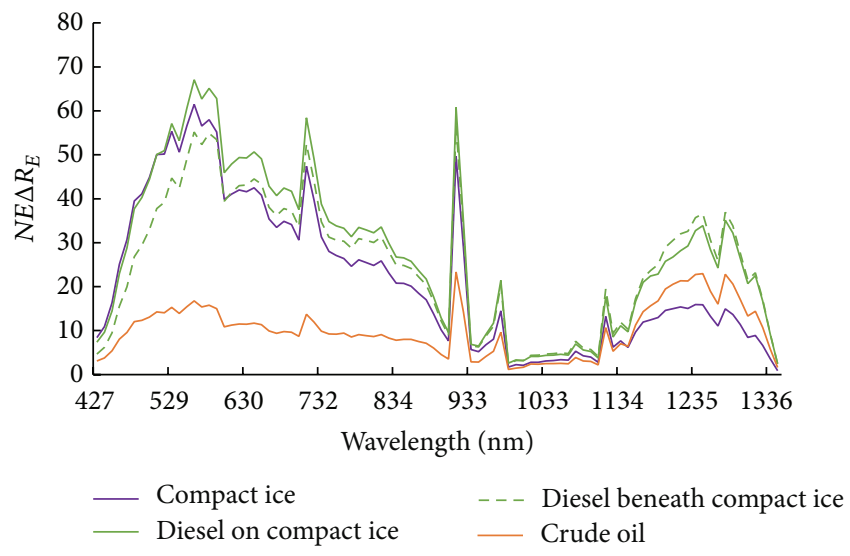

(c)

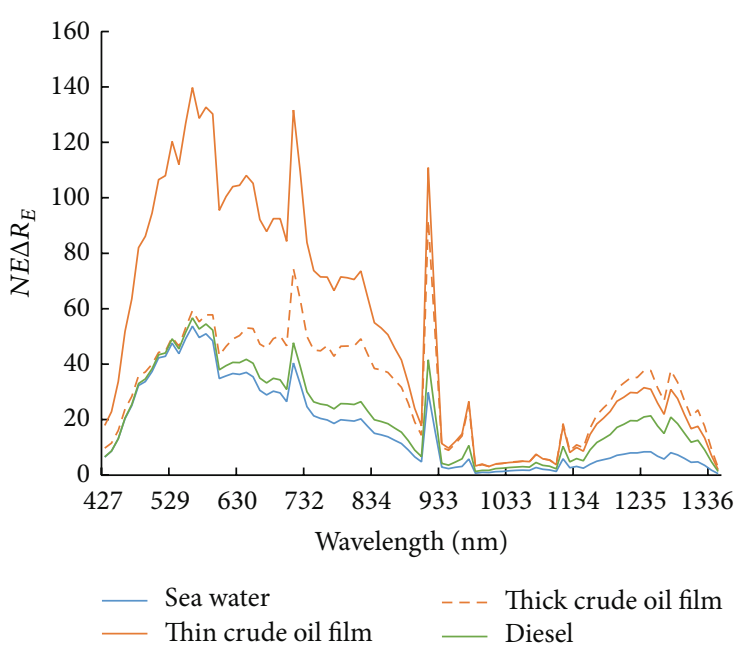

(b)

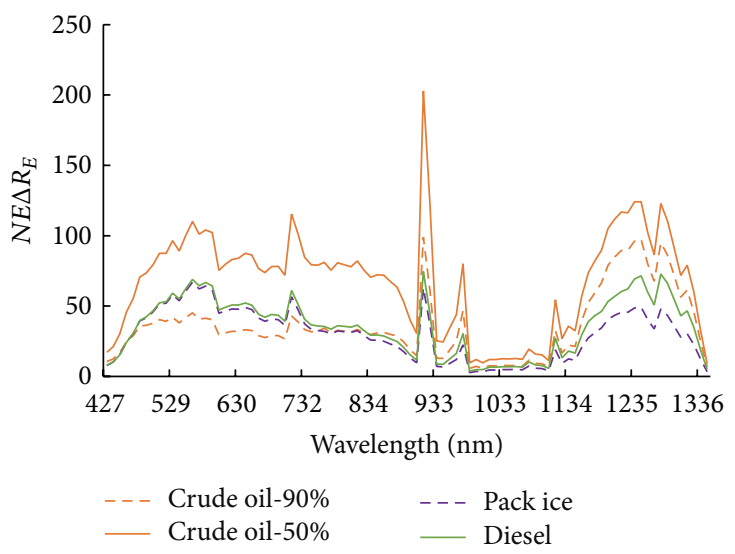

(d)

Figure 5: Reflectance spectra normalized to $N E \Delta R_{E}$.

The $N E \Delta R_{E}$ spectrum of crude oil film on the compact ice shows that a significant difference exists from the water (Figure 5(c)), a finding that implies that crude oil could be distinguished from the water easily. The difference is mainly caused by the stronger absorption of light by the crude oil compared with the water. When diesel oil was on the surface of compact ice, it was not detectable by the bands shorter than $559 \mathrm{~nm}$. However, when it was under the thin sea ice, it reflected much differently from the sea ice at all the wavelengths. Light reflected by the sea ice could penetrate the oil film when the diesel was put on the sea ice, and thus the received energy by the sensor included the reflected light from both sea ice and oil film. For light shorter than $559 \mathrm{~nm}$, it was reflected by both the ice and oil film. On account of the thickness of the diesel, the reflected short wave light is mainly from the sea ice. For the longer wavelength, the oil film reflected the light, while the ice absorbed it, resulting in the greater difference between compact ice and oil film. The relatively much greater difference between compact ice and diesel under the ice is caused by the reflected effect at the iceoil-water interfaces [39].
As shown in Figure 5(d), $N E \Delta R_{E}$ of crude oil in pack ice has a significant difference from that of the ice, while the diesel does not clearly differ from ice. If the crude oil covered $50 \%$ area of the sea ice, the value of $N E \triangle R_{E}$ would be much greater than the pack ice, meaning that the oil in the pack ice could be distinguished easily through the visibleto-infrared bands. However, when the coverage increased to $90 \%$, the bands shorter than $468 \mathrm{~nm}$ and in the range of $752-$ $824 \mathrm{~nm}$ were not suitable to separate crude oil from pack ice. This result may have the same reason as the crude oil on the water. The $N E \triangle R_{E}$ spectrum of diesel has a slight difference from the pack ice in the visible and shortwave infrared region, implying that it is difficult to identify diesel within the pack ice via these bands. Given that the diesel is on the water, the discrepancy between pack ice and diesel dramatically increased in the region greater than $1134 \mathrm{~nm}$. This increase may be due to the reflection of long wave electromagnetic energy by the oil film, whereas the water almost fully absorbs it.

The sensitivity of each band to discriminate oil film from the uncontaminated background, water, compact ice, and pack ice is illustrated in Figure 6. In general, the hyperspectral 


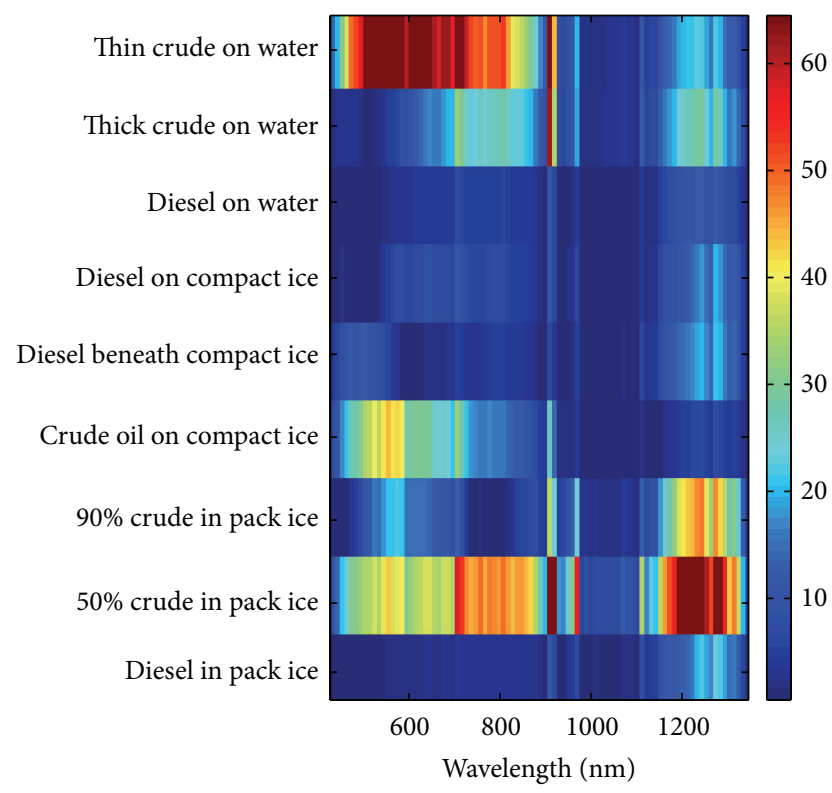

FIgURE 6: Difference of the $N E \Delta R_{E}$ value between oil and the uncontaminated water or ice.

sensor is more sensitive to the crude oil than to diesel in various scenes. The visible and infrared bands, from $468 \mathrm{~nm}$ to $933 \mathrm{~nm}$, are more suitable to identify the contaminant. In addition, when the background is pack ice, the infrared region from $1134 \mathrm{~nm}$ to $1326 \mathrm{~nm}$ is another potential useful zone. Through the visible-to-infrared bands, the sensitivity to the existence of diesel is inferior to the crude oil. Relatively, the bands greater than $1134 \mathrm{~nm}$ have the potential to separate diesel from the water or sea ice.

\section{Conclusions}

Optical remote sensing sensors are able to detect the wavelength-dependent reflectance of oil slicks within sea ice. Using two representative oils, we showed that both oil type and background are critical for the application of optical remote sensing to identify oil in ice-infested waters. Crude oil from Liaohe oilfield was theoretically detectable by the sensor under all conditions. Diesel used as fuel by the YUKUN vessel was found to be slightly different from the water and ice.

In this work, we investigated three oil spill conditions: oil on water surface, oil with compact ice, and oil with pack ice. Taking no account of the spatial scale effect, both the visible and the near-infrared bands are suitable to detect crude oils in all three scenarios. The longer infrared bands have more potential to discriminate diesel from water and ice relatively.

Note that the experiment was carried out in a windless environment with very thin sea ice, which may cause discrepancy from reality. The reflectance characteristics of oil in a thick ice-covered area should be studied in future research.

\section{Competing Interests}

All authors declare that they have no competing interests.

\section{Acknowledgments}

This work was supported by the National Natural Science Foundation of China (Grant nos. 51509030 and 41571336), Natural Science Foundation of Liaoning Province (Grant no. 2015020081), the National Key Technology R\&D Program (Grant no. 2015BAG20B04), and the Fundamental Research Funds for the Central Universities (Grant no. 3132015006).

\section{References}

[1] C. Ke, H. Peng, B. Sun, and H. Xie, "Spatio-temporal variability of Arctic sea ice from 2002 to 2011," Journal of Remote Sensing, vol. 17, no. 2, pp. 452-466, 2013.

[2] SafetyforSea, NSR Navigation Season Comes to End with Record Numbers, 2013.

[3] B. Lyu, Study on the Environmental Factors of Arctic Navigation and the Safety Measures for Navigation in Ice Area, Dalian Maritime University, Dalian, China, 2012.

[4] V. Ruoppolo, E. J. Woehler, K. Morgan, and C. J. Clumpner, "Wildlife and oil in the Antarctic: a recipe for cold disaster," Polar Record, vol. 49, no. 2, pp. 97-109, 2013.

[5] D. F. Dickins, J. Bradford, and L. Steinbronn, Detection of Oil on and Under Ice: Phase III-Evaluation of Airborne Radar System Capabilities in Selected Arctic Spill Scenarios, United States Department of Interior Minerals Management Service, 2008.

[6] Nuka Research and Planning Group and Pearson Consulting, Oil Spill Prevention and Response in The U.S. Arctic Ocean: Unexamined Risks, Unacceptable Consequences, U.S. Arctic Program, Pew Environment Group, 2010.

[7] I. Leifer, W. J. Lehr, D. Simecek-Beatty et al., "State of the art satellite and airborne marine oil spill remote sensing: application to the BP Deepwater Horizon oil spill," Remote Sensing of Environment, vol. 124, pp. 185-209, 2012.

[8] M. Fingas and C. Brown, "Review of oil spill remote sensing," Marine Pollution Bulletin, vol. 83, no. 1, pp. 9-23, 2014.

[9] S. Skrunes, C. Brekke, and T. Eltoft, "Characterization of marine surface slicks by radarsat-2 multipolarization features," IEEE Transactions on Geoscience and Remote Sensing, vol. 52, no. 9, pp. 5302-5319, 2014.

[10] R. D. Lindsley, "Scatterometer use for oil spill measurements," IEEE Aerospace and Electronic Systems Magazine, vol. 27, no. 5, pp. 42-43, 2012.

[11] S. Akar, M. L. Süzen, and N. Kaymakci, "Detection and objectbased classification of offshore oil slicks using ENVISAT-ASAR images," Environmental Monitoring and Assessment, vol. 183, no. 1-4, pp. 409-423, 2011.

[12] C. Anderou and V. Karathanassi, "Exploitation of hyperspectral imagery for the detection of oil spill characteristics," in Proceedings of the 12th International Conference on Environmental Science and Technology (CEST '11), Rhodes, Greece, October 2011.

[13] C. Brekke and A. H. S. Solberg, "Oil spill detection by satellite remote sensing," Remote Sensing of Environment, vol. 95, no. 1, pp. 1-13, 2005.

[14] F. M. F. Salem, Hyperspectral Remote Sensing a New Approach for Oil Spill Detection and Analysis, George Mason University, Fairfax, Va, USA, 2003. 
[15] E. Vahtmäe, T. Kutser, G. Martin, and J. Kotta, "Feasibility of hyperspectral remote sensing for mapping benthic macroalgal cover in turbid coastal waters-a Baltic Sea case study," Remote Sensing of Environment, vol. 101, no. 3, pp. 342-351, 2006.

[16] F. Van der Meer, P. Van Dijk, S. Kroonenberg, H. Yang, and H. Lang, "Hyperspectral hydrocarbon microseepage detection and monitoring: potentials and limitations," in Proceedings of the 2nd EARSeL Workshop on Imaging Spectroscopy, Enschede, The Netherlands, July 2000.

[17] Z. Wang, M. Fingas, and D. S. Page, "Oil spill identification," Journal of Chromatography A, vol. 843, no. 1-2, pp. 369-411, 1999.

[18] B. Liu, Y. Li, P. Chen, and X. Zhu, "Extraction of oil spill information using decision tree based minimum noise fraction transform," Journal of the Indian Society of Remote Sensing, pp. $1-6,2016$.

[19] M. Lennon, S. Babichenko, N. Thomas, V. Mariette, G. Mercier, and A. Lisin, "Detection and mapping of oil slicks in the sea by combined use of hyperspectral imagery and laser induced fluorescence," EARSeL eProceedings, vol. 5, no. 1, pp. 120-128, 2006.

[20] S. U. Din, A. Al Dousari, and P. Literathy, "Evidence of hydrocarbon contamination from the Burgan oil field, Kuwaitinterpretations from thermal remote sensing data," Journal of Environmental Management, vol. 86, no. 4, pp. 605-615, 2008.

[21] G. Cai, J. Wu, Y. Xue, W. Wan, and X. Huang, "Oil spill detection from thermal anomaly using ASTER Data in Yinggehai of Hainan, China," in Proceedings of the IEEE International Geoscience and Remote Sensing Symposium (IGARSS '07), pp. 898-900, Barcelona, Spain, June 2007.

[22] J. W. Salisbury, D. M. D’Aria, and F. F. Sabins Jr., “Thermal infrared remote sensing of crude oil slicks," Remote Sensing of Environment, vol. 45, no. 2, pp. 225-231, 1993.

[23] D. Dickins, J. H. S. Andersen, P. J. Brandvik et al., Remote Sensing for the Oil in Ice Joint Industry Program 2007-2009, JIP, 2012.

[24] D. Dickins, P. J. Brandvik, J. Bradford, L.-G. Faksness, L. Liberty, and R. Daniloff, "Svalbard 2006 experimental oil spill under ice: remote sensing, oil weathering under arctic conditions and assessment of oil removal by in-situ burning," in Proceedings of the International Oil Spill Conference (IOSC '08), pp. 681-688, Savannah, Ga, USA, May 2008.

[25] K. Butt, P. O'Reilly, and E. Reimer, A Field Evaluation of Impulse Radar for Detecting Oil in and Under Sea Ice, C-CORE, St, AB, Dome Petroleumm Calgary, 1981.

[26] T. Nedwed, L. Srnka, and H. Thomann, "Remote detection of oil spilled under ice and snow using nuclear magnetic resonance," in Proceedings of the Arctic and Marine Oilspill Program Technical Seminar, Environment Canada, Calgary, Canada, June 2008.

[27] J. H. Bradford, D. F. Dickins, and P. J. Brandvik, "Assessing the potential to detect oil spills in and under snow using airborne ground-penetrating radar," Geophysics, vol. 75, no. 2, pp. G1G12, 2010.

[28] M. Fingas and C. Brown, "A review of the status of advanced technologies for the detection of oil in and with ice," Spill Science \& Technology Bulletin, vol. 6, no. 5-6, pp. 295-302, 2000.

[29] R. Dick and M. F. Fingas, "First results of airborne trials of a 64-channel laser fluorosensor for oil detection," in 16th Arctic and Marine Oil Spill Program Technical Seminar, pp. 365-380, Environment Canada, 1992.
[30] J. Praks, M. Eskelinen, J. Pulliainen, T. Pyhalahti, and M. Hallikainen, "Detection of oil pollution on sea ice with airborne and spaceborne spectrometer," in Proceedings of the IEEE International Geoscience and Remote Sensing Symposium (IGARSS '04), pp. 273-276, Anchorage, Alaska, USA, September 2004.

[31] F. E. Nicodemus, J. C. Richmond, J. J. Hsia, I. W. Ginsberg, and T. Limperis, Geometrical Considerations and Nomenclature for Reflectance, National Bureau of Standards, US Department of Commerce, Washington, DC, USA, 1977.

[32] X. Xu, Physical Theory of Remote Sensing, Peking University Press, Beijing, China, 2005.

[33] M. Wettle, P. J. Daniel, G. A. Logan, and M. Thankappan, "Assessing the effect of hydrocarbon oil type and thickness on a remote sensing signal: a sensitivity study based on the optical properties of two different oil types and the HYMAP and Quickbird sensors," Remote Sensing of Environment, vol. 113, no. 9, pp. 2000-2010, 2009.

[34] A. G. Dekker and S. W. M. Peters, "The use of the Thematic Mapper for the analysis of eutrophic lakes: a case study in the Netherlands," International Journal of Remote Sensing, vol. 14, no. 5, pp. 799-821, 1993.

[35] M. Wettle, V. E. Brando, and A. G. Dekker, "A methodology for retrieval of environmental noise equivalent spectra applied to four Hyperion scenes of the same tropical coral reef," Remote Sensing of Environment, vol. 93, no. 1-2, pp. 188-197, 2004.

[36] B.-X. Liu and Y. Li, "A methodology for retrieval of environmental noise equivalent radiance of remote sensing images," Journal of Dalian Maritime University, vol. 38, no. 3, pp. 105-111, 2012.

[37] Y. Li, B. Liu, B. Li, and D. Chen, "Analysis of spectral characteristics of oil film on water based on wavelet transform," Spectroscopy and Spectral Analysis, no. 7, pp. 1923-1927, 2012.

[38] B. Liu, W. Zhu, and Y. Li, "Spectral characteristics analysis of oil film among sea ice," in Proceedings of the IEEE International Geoscience and Remote Sensing Symposium (IGARSS '15), pp. 3450-3453, IEEE, Milan, Italy, July 2015.

[39] Y.-C. Lu, Q.-J. Tian, X.-P. Qi, J.-J. Wang, and X.-C. Wang, "Spectral response analysis of offshore thin oil slicks," Spectroscopy and Spectral Analysis, vol. 29, no. 4, pp. 986-989, 2009. 

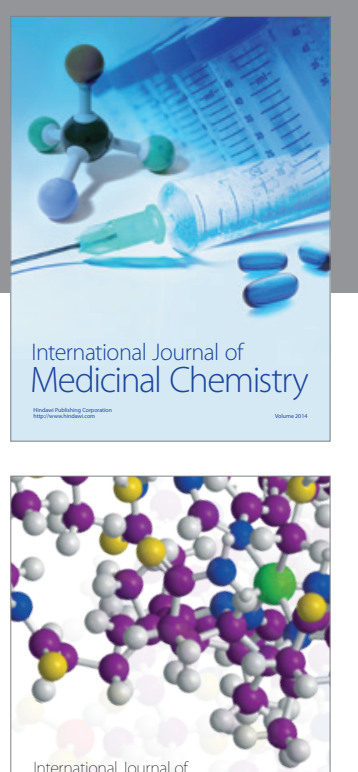

Carbohydrate Chemistry

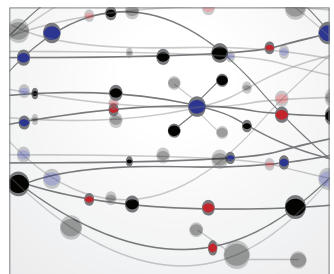

The Scientific World Journal
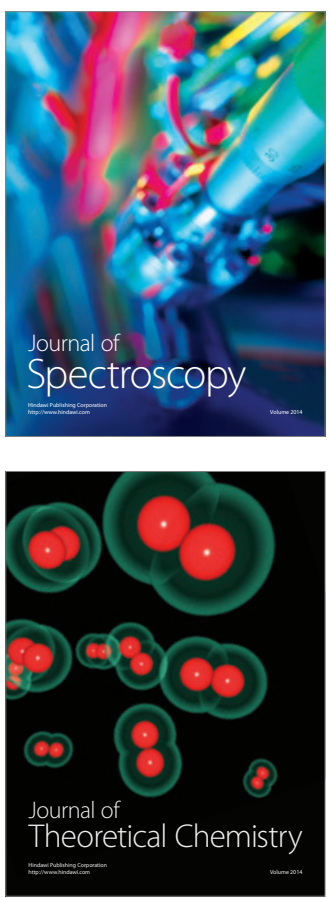
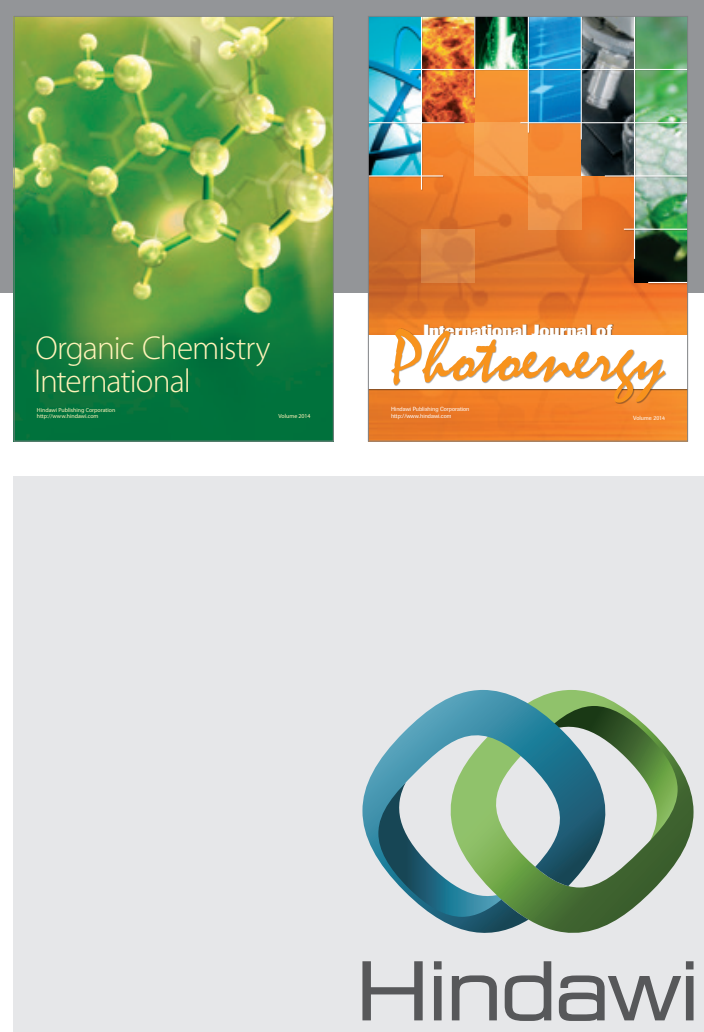

Submit your manuscripts at

http://www.hindawi.com

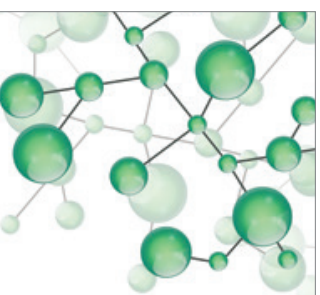

International Journal of

Inorganic Chemistry

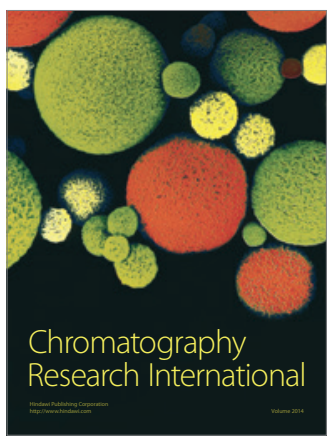

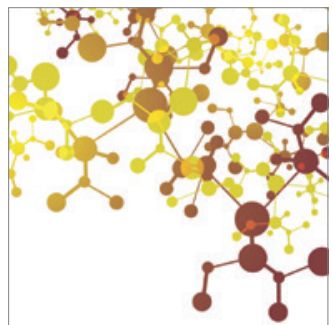

Applied Chemistry
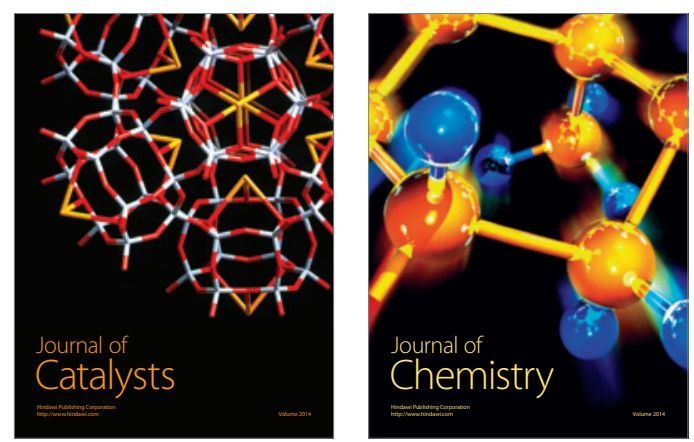
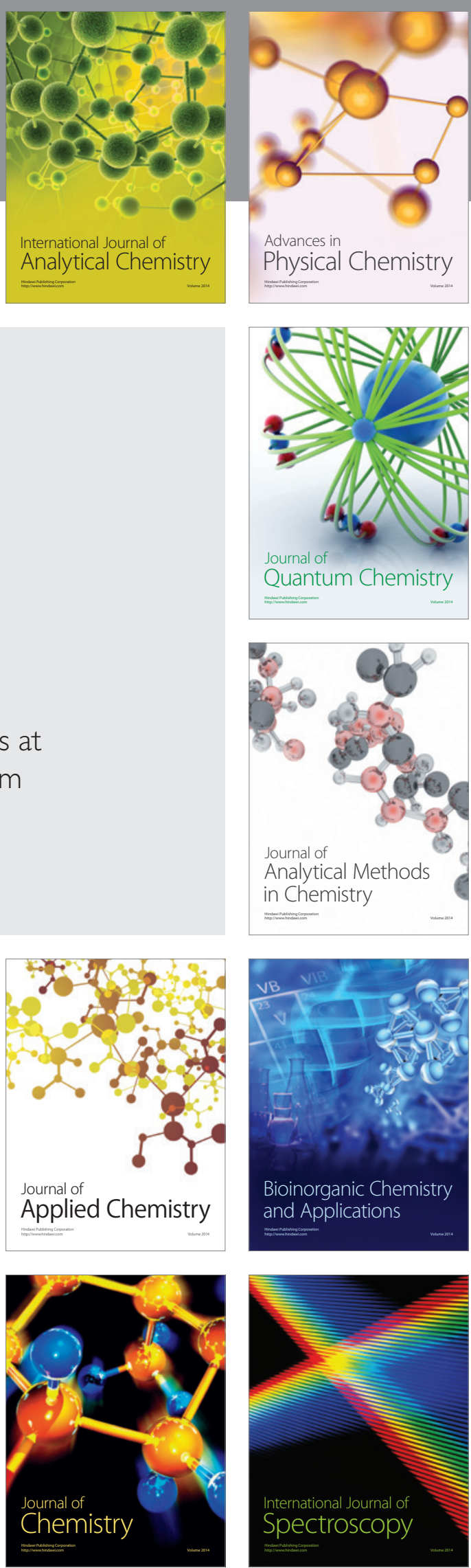